\title{
Research on Approaches of Cultivating Innovative Ability of Academic Postgraduate
}

\author{
Zhi-Yu ZHOU ${ }^{1, a,{ }^{*}, \text { Di-Chong WU }}{ }^{2, b}$, Feng FU ${ }^{1}$ \\ ${ }^{1}$ College of Information, Zhejiang Sci-Tech University, Hangzhou, Zhejiang, 310018, China \\ ${ }^{2}$ Business Administration College, Zhejiang University of Finance \& Economics, Hangzhou, \\ Zhejiang, 310018, China \\ azhouzhiyu1993@163.com, b1601441815@qq.com \\ ${ }^{*}$ Corresponding author
}

Keywords: Open teaching, Teachers team, Scientific research and training, Innovation ability.

\begin{abstract}
The cultivation of high-quality talents of innovative spirit and innovation ability is not only an important issue that significant to theory study and practice exploration, but it is also an knotty problem need to be solved when college promotes the development of postgraduate. In this paper, we present an open school concept and emphasize the important role of building teacher's team in broaden postgraduate' research ideas, combined with the practice of teaching and research training to cultivate innovative thought, and thereby enhancing the innovation capacity and academic competition of postgraduates.
\end{abstract}

\section{Introduction}

Academic postgraduate is an important part in college innovative group, is building an innovative country's major source of talent, and it's also the pioneer of country's science and technology. Academic graduate student innovative ability is an important part of Innovation in Higher Education, and meanwhile, teaching innovation is the core of educational innovation. Postgraduate innovation capability directly affects the country's independent innovation capability, so the core mission of improving the quality of academic postgraduate education is to raise awareness of innovation and creativity.

The method to training academic postgraduate creativity has become a hot topic. Based on the analysis of postgraduate training mode on the basic elements, Yao [1] built innovative postgraduate training mode from training objectives, training process, and curriculum and quality management. To effectively improve the innovation ability of graduate students, Tang [2] proposed to create an open academic environment, optimize the knowledge structure of graduate students, strengthen teacher's responsibility, and build innovation base and platform for graduate students' creative and practical ability. Li [3] suggested to strengthen the cultivation of innovative abilities of postgraduate by establishing postgraduate education reform funds, developing school-enterprise cooperation, building postgraduate training base, setting up to carry out postgraduate academic forums and dissertations innovation base. Pan [4] discussed the meaning of student's ability on innovation, and analyzes the key points to build innovative postgraduate education platform, summarizes a series of achievements made in the School of Mechanical and Electrical Engineering in innovative talents training process. To resolve the problems exist in ordinary college during experimental teaching, Ma [5] proposed to develop self-learning-based modeling and ideas use simulation examples in teaching system. Ma [6] proposed multi-angle, multi-method teaching collaborative culture conceived in order to maximize the potential of graduate students and to foster innovative awareness and skills. Feng [7] put forward corresponding improvement measures from the educational concept, the education system, teaching methods, teacher's team building and innovation environment. Gu [8] described the approach to promote the development of innovative capability of postgraduate from the building covering multi-dimensional content, hierarchy optimization and system that core value is motivation to develop the innovation of postgraduate. Zhu [9] proposed to produce the number and quality of innovations depends more on the promotion 
of graduate students' characteristic of thought and the construction of knowledge system.

With enrollment of graduate students, some academic postgraduate keen to master practical skills, lack of innovative passion and consciousness, and can hardly focus on scientific research. Therefore, in order to train students to establish academic sense of innovation, increase innovative awareness, improve innovative capabilities, it is necessary to explore new ways to open training graduate students, promote the new model emphasizing graduate training in team building supervisor, discuss the new system combining practice teaching and scientific training.

\section{Open educational philosophy}

Firstly, the open concept of innovative education refer to the open of teaching content, then, promptly put the discipline of new scientific research and new scientific concept into teaching content, while establishing an open mechanism interdisciplinary group of disciplines to form interdisciplinary fusion of innovative education. In addition, the education of postgraduate should strengthen international educational exchanges and cooperation to fully digest and absorb advanced technology and knowledge. To adapt to the trend of internationalization of postgraduate education, we should keep up with high-level universities in all aspects of education ideas, teaching methods, teaching conditions, and constantly absorbing advanced foreign teaching ideas and teaching methods, and to create more opportunities for learning international academic developments. Strengthen international exchanges and cooperation, and explore new ways to open training graduate students, develop an international perspective and international competitiveness of graduate students, while a certain extent, and promote cooperation and exchanges with overseas instructors tutor. Open philosophy of education, promote postgraduate study abroad experience, broaden academic horizons of postgraduate, and then improve innovative capability and awareness.

\section{Emphasize the tutor team construction in the training of graduate students}

The training mode of graduate students' innovation ability as a comprehensive reflection of culture idea and goal of postgraduates has important value on the fostering of postgraduates. The tutor plays a decisive role in graduate education, is the graduate student education level managers, and has an important responsibility to cultivate the quality of graduate students. The tutor should not only be responsible for guiding the graduate school to graduate, clearly put forward the task of learning, helping students with learning plan, choice of courses, to gradually graduate cultivation independent scientific research and innovation ability. The development of science and technology, make the cross penetration of various disciplines have become increasingly prominent, professional between more closely linked, challenges the knowledge structure and knowledge update of Supervisor. The traditional single tutor model has been unable to meet the development needs of the innovation ability of graduate students, tutors team system has become a new form of guidance.

The construction of the supervisor team of training graduate students not only improve the graduate student innovation ability, but also provide a good platform to enhance their own academic level of postgraduate tutors. The realization of cross disciplines is an effective way to produce innovative point. It is hard to succeed in important scientific research or work on personal. Many significant achievements in scientific research have the team cooperation and support. No team spirit of collaboration, collaborative research, it is difficult to produce great innovation achievements. Has the team cooperation consciousness is an important quality of contemporary graduate, teamwork is to show the individual talent in the team, so that each person's potential into full play. Adhere to the tutor team security innovation training, cultivating the sense of team cooperation, adhere to the extensive cooperation to expand the research field of vision, on the academic front dynamic, make graduate innovative practice ability and the team cooperation ability to be strengthened. Mutual discussion between graduates in tutor team, often mutually inspire, produces the creative thinking, is a great help to broaden their thinking, improve the scheme and enhance the level. The construction of the tutor team of training students have a unique condition to carry out interdisciplinary joint training of graduate students, can make full use and integration of 
resources, to achieve a win-win situation between the tutors.

The author has presided over the research on Key Technologies of robot autonomous navigation based on stereo vision in natural environment" (number: LY13F030013) and "target vision analysis based on grey modeling" (number: Y1090256) of Zhejiang Province Natural Science Fund Project, presided over the textile science and engineering of Zhejiang province priority level discipline open fund project "color classification and illumination correction of dyed goods algorithm based on computer vision". Mentor team members have the experts engaged in machine vision, researchers have engaged in the grey system theory, there are researchers engaged in pattern recognition theory and robot navigation technology, also has the researchers and master/doctor have engaged in dyed goods detection, team members have reasonable structure. Other members in tutor team have hosted National Natural Science Fund project on computer vision in the dyeing product defect detection and dyed goods detection, have rich experience in research related disciplines, can ensure the smooth progress of the after funded projects. The graduate Guidance Group of complementary specialty advantages and professional knowledge alliances has laid the good foundation for the training of graduate student innovation ability.

\section{Innovation ability training based on the practice of teaching and research training}

As the basic theory and professional knowledge of academic graduate students research after the expansion is not complete, study ability is weak, the academic field of vision should be broadened, so teachers guide and promote is particularly important. Guide the academic graduate students independent thinking, encourage them to play the subjective initiative, pay special attention to guide the academic graduate students grasp some details of further exploration and study, to maximize their potential, and to cultivate the spirit of innovation. Author makes the graduate students involved in the research project hosted by tutor team to guide them, in the early let them select interest topics, and then a small subject that include the realization of the concrete implementation scheme of this subject and documents to solve the issue is given by tutor team, guide the graduate study in the whole process. In the late student independent innovation oriented training mode of graduate students, encourage free play based on the previous research on innovation, and further research in a specific field of study, thus forming the graduate unique insights. But the graduate students in the difficulties and setbacks and failures, will graduate cultivating the spirit of perseverance, the problems in the experiments and unexpected experimental results, encourage students to question and explore. Conduct regular postgraduate studies reporting system, is conducive to the graduate timely summary of achievements in scientific research, improve research paper writing ability of the students. At the same time, the implementation of flexible educational system, graduate students can adjust the learning plan according to the actual situation, to shorten or extend school hours, expand the study on the autonomy of students learning.

The cultivation of innovative ability is the core problem of postgraduate education, and the consciousness of scientific research, scientific knowledge and scientific research ability is the foundation of the innovation ability of graduate students. In order to improve graduate innovative ability, presided over take a heuristic education and training of graduate student's consciousness of scientific research, scientific knowledge and scientific research ability by the author's Zhejiang Province Natural Science Fund Project to improve the innovative ability of graduate students. At the completion of the Zhejiang Province Natural Science Fund Project "target vision analysis based on grey modeling", through guiding the study of students' learning research, training postgraduate the basic knowledge of research and scientific research consciousness in the theory of grey system, target tracking and target behavior understanding, inspire graduate proposed research methods, to improve the graduate research knowledge and ability of scientific research. In the process of presided over the Zhejiang Province Natural Science Fund Project "Key Technologies of robot autonomous navigation based on stereo vision in natural environment", based upon our previous projects, training postgraduate basic knowledge in stereo vision, obstacle detection and motion control of robot, through scientific research accumulation to accelerate training rate of graduate scientific research ability. Presided over the textile science and engineering of Zhejiang province 
priority among priorities first level discipline of open fund project "color classification and illumination correction of dyed goods algorithm based on computer vision", using the team of graduate students in the research of computer vision technology accumulation, inspired graduate in dye chromaticity color classification and illumination correction proposed innovation algorithm. This heuristic education based on the scientific research item, improve graduate innovative and engineering ability, cultivate postgraduates, dare to dare to criticize the surpassing and creating, dare to challenge the authority of the courage and habits.

In this paper, we combine practice teaching and innovation capacity training for scientific research aim to explore and establish system that both impart knowledge, but also to improve the practical ability of postgraduate, and including research thinking and self-learning ability mode, so that students can not only accurately understand and master the knowledge, will use knowledge and ability to acquire new knowledge of the formation, training graduate students sense of collaboration and teamwork, as well as exercise the ability to put up with a multidisciplinary collaboration solutions to complex problems. Therefore, the use of research resources and cooperation of mentors, and guide students through technological innovation activities focus on domestic and foreign high-tech and advanced technology, promote the interest of postgraduate to research by combining knowledge learned and practical application, and it is all important to enhance the innovation ability of postgraduate.

\section{Conclusion}

Graduate education is main channel to train high-level expertise and innovative talents, the essential characteristic and vitality of graduate education are develop creative spirit and innovation capacity in practice. In this paper, we explore new ways to open training graduate students, promoting the new model emphasizing building team supervisor in graduate training, discusses the model of combining practical teaching and research training, to train students to establish academic sense of innovation, increase innovation awareness, improve innovation capacity to accommodate the demand for innovative and creative thinking ability of senior personnel. The author believes the postgraduate innovation training focuses on the creation of innovative thinking, open educational philosophy and base on a mentor team, combined with the practice of teaching and research training, to stimulate students interest and passion for innovation research, highlighting the individual talent in teamwork, so we can foster postgraduate innovation capacity.

\section{Acknowledgement}

This research was financially supported by the postgraduate research project of education and teaching reform of Zhejiang Sci-Tech University (YJG-Z14001) and the postgraduate research project of education and teaching reform of Institute of information (Information policy No. [2014] $15)$.

\section{References}

[1] Yao Jie, Zhu Peijun. Study on the Training Mode of Innovative Graduate Students. Journal of Northeast Dianli University, 2012, 32(5): 75-77.

[2] Tang Kunxiong. On the Construction and Implementation of the Postgraduates' Ceative Ability Training System. Journal of Guizhou Normal University: Social Science, 2014, 91):23-27.

[3] Li Jingbo ,Chai Yuling. A Study of Innovative Pattern of Education of Graduate Students. Theory and Practice of Education, 2010, 30(5): 10-11.

[4] Pan Li, Ji Shiming, Lu Congda. The Cultivation of Creative Talents Based on the Innovation Education Platform. Heilongjiang Researches on Higher Education, 2006, (3):124-126.

[5] Ma Yuzhen, Song Fangzhen, Shao Haiyan. Application of modeling and simulation examples 
teaching in postgraduate innovative education. Experimental Technology and Management, 2012, 29(6): 86-89.

[6] Ma Yuzhen, Dong Xueren, Song Fangzhen. Collaborative teaching in innovative education of graduate students. China Modern Educational Equipment, 2013, (1): 86-88.

[7] Feng Li. On the status quo and the improving strategy for postgraduates' innovative education of our country. Journal of Chongqing Education College, 2011, 24(2): 125-126.

[8] Gu Yuehua. Study on training system construction for promoting postgraduates' innovation capacity development. Journal of Zhejiang Sci-Tech University, 2014, 32 (6): 456-460.

[9] Zhu Hong, Li Wenli, Zuo Zujing. The Status of Graduate Students' Creativity and Its Influence Mechanism. Journal of Higher Education, 2011, 32(2):74-82. 